\title{
Editorial
}

\section{Fetal origins of coronary heart disease}

Recent findings suggest that the pathogenesis of coronary heart disease begins in utero. Babies who are small at birth or in infancy have high rates of coronary heart disease, stroke, hypertension, and diabetes in adult life. ${ }^{1-3}$ This is found in babies who are born small for their gestational age rather than in those born prematurely. ${ }^{2}$ The effect is not confined to babies with intrauterine growth retardation defined by birth weight at the lowest centiles for gestational age, but is seen in babies of average or above average weight. Some of these babies are small in relation to the size of their placentas ${ }^{2}$; others are thin at birth, or short in relation to the size of their heads ${ }^{4}$; in others average birth weight is followed by below average infant weight gain.'

\section{Programming}

One interpretation of these findings is that processes associated with low rates of fetal and infant growth programme cardiovascular disease and diabetes. Numerous animal experiments have shown that poor nutrition, and other influences that reduce growth during critical periods of early life, may permanently affect the structure and physiology of a range of organs and tissues. ${ }^{5-8}$ This is known as programming. A simple example in humans is the permanent deformity of the pelvic bones caused by rickets in infancy. The long-term consequences of early growth constraint depend on its timing, because different tissues mature at different stages of fetal life and infancy. Consistent with this, babies with different patterns of reduced fetal growth have different abnormalities as adults.

\section{Geographical studies}

Surprisingly perhaps it was geographical studies that gave the first clue that coronary heart disease might be a consequence of impaired early development of blood vessels, the liver, endocrine pancreas, and other tissues. An analysis of the large differences in death rates from coronary heart disease between different areas of England and Wales showed that they paralleled similar differences in neonatal mortality in the early years of the century. ${ }^{9}$ In those days high neonatal mortality in a population indicated a high incidence of low birth weight and poor maternal nutrition.

The idea that coronary heart disease may arise in childhood is familiar, but the hypothesis that it is importantly determined by early adaptations to the maternal environment, in utero and during infancy, is a new point of departure for cardiovascular research. The effects of programming are now being systematically explored in studies of middle-aged and elderly adults whose birth measurements and infant growth were recorded. From 1911 onwards every baby born in the county of Hertfordshire was weighed at birth, visited periodically by a health visitor throughout the first year, and weighed again at one year of age. ${ }^{1}$ Records of these visits have sur- vived so that it is possible to trace men and women born 60 and more years ago and to relate their early measurements to the later occurrence of illness and death and to the levels of known risk factors for cardiovascular disease. Similar long-term follow up studies are being carried out in Preston and Sheffield where 50 years ago maternity hospitals made unusually detailed measurements on all newborn babies.

The first study in Hertfordshire was of 5600 men born in the eastern part of the county between 1911 and 1930 . Those who weighed 18 pounds $(8.2 \mathrm{~kg})$ or less at one year of age had death rates from coronary heart disease that were almost three times greater than among those who weighed 27 pounds $(12.3 \mathrm{~kg})$ or more. ${ }^{1}$ Death rates fell progressively with increasing weight at one year. There were similar, though less strong, trends with birth weight. The same trends have recently been shown in women (unpublished, C H D Fall).

\section{Studies of individuals}

Examination of samples of men and women still living in Hertfordshire and Preston has shown that birthweight and infant weight are associated with adult blood pressure; glucose tolerance; plasma concentrations of fibrinogen, factor VII, and apolipoprotein B; and with a tendency to store fat abdominally rather than peripherally..$^{2-410}$ These associations parallel those with death rates from cardiovascular disease in that higher early weight is associated with lower levels of each risk factor. The associations are remarkably strong and graded. For example, the prevalence of impaired glucose tolerance or noninsulin dependent diabetes among men aged 64 years falls progressively from $40 \%$ among those with birth weights of 5.5 pounds or less to $14 \%$ among those with birth weights of 9.5 pounds or more. ${ }^{3}$ Among men with birth weights of 6.5 pounds the risk of developing syndrome $\mathrm{X}$ (hypertension, diabetes and lipid disorders) is ten times greater than among men with birth weights of more than 9.5 pounds. ${ }^{11}$

A striking feature of these findings is that different risk factors are each related to different patterns of early growth. For example, blood pressure is related to birth weight but not independently to weight at one year. ${ }^{4}$ This suggests that the critical period when blood pressure is sensitive to programming is during fetal life not infancy. In contrast, plasma total and low density lipoprotein cholesterol concentrations are related to the method and duration of infant feeding. Men who were exclusively bottle fed or breast fed beyond one year have high plasma cholesterol concentrations and high death rates from coronary heart disease. ${ }^{10}$ These findings echo experiments on animals showing that lipid metabolism can be programmed by early feeding. ${ }^{78}$

Reduced early growth leads to higher levels of coronary risk factors within each social class. Where a risk factor is influenced by adult lifestyle (for example, plasma fibrinogen by smoking or impaired glucose tolerance by obesity) 
the effects of lifestyle add to those of early growth. ${ }^{12}$ Thus the highest prevalence of impaired glucose tolerance is found in people who had low birth weight but are currently obese. ${ }^{3}$ Critics of research into programming nevertheless maintain that people who had constrained early growth may continue to be exposed to an adverse environment in childhood and adult life, and it may be this later environment which produces the effects now being attributed to impaired early development. ${ }^{13}$ This criticism is unlikely to be correct. The relations with early growth constraint are strong, graded, and specific and are supported by animal research. It is more reasonable to attribute them to programming than to unknown influences in the adult environment defined only in such general terms as "psychosocial stress".

\section{The future}

The conclusion that coronary heart disease is programmed raises several questions. What influences fetal growth? How does the fetus respond? How are the longterm cardiovascular, metabolic, and endocrine consequences programmed? Answers to these are beginning to emerge.

A set of obstetric records in Sharoe Green Hospital, Preston, provided the opportunity to examine groups of men and women, now aged around 50 years, whose measurements at birth were recorded in detail. In those who had had large placentas in relation to their birth weight systolic pressure was more than $20 \mathrm{~mm} \mathrm{Hg}$ higher. Disproportionately large placental size is a recognised consequence of maternal undernutrition. It occurs in babies whose mothers were anaemic during pregnancy, and can be produced in sheep by depriving the ewe of food in early pregnancy. ${ }^{14-16}$ Maternal undernutrition is suspected as an important influence which slows fetal growth and programmes coronary heart disease. ${ }^{12}$ Recent studies of 4 year old children in Salisbury have shown that those who had large placental weight in relation to birth weight have higher blood pressure, in the same way as in older people. ${ }^{17} \mathrm{We}$ must therefore conclude that maternal undernutrition still affects fetal growth today, a conclusion that is consistent with the high incidence of pregnancy anaemia. ${ }^{1517}$

Studies of glucose tolerance are giving an insight into the processes whereby impaired early development leads to adult disease. Low weight gain in fetal life and infancy is associated with raised plasma concentrations of 32-33 split proinsulin in adult life, evidence of insulin production by a relatively small complement of pancreatic $\beta$ cells. ${ }^{3}$ The $\beta$ cells develop during fetal life and in infancy and impaired development of the endocrine pancreas is a feature of intrauterine growth retardation. It is proposed that nutritional and other influences which impair early growth reduce the $\beta$ cell mass. If this is followed by attrition of $\beta$ cells with aging or by insulin resistance, usually in association with obesity, non-insulin dependent diabetes will develop.

Research into the fetal origins of coronary heart disease is now being carried out in several centres. We can expect to know considerably more about it in the near future.

MRC Environmental Epidemiology Unit,

D J P BARKER

Southampton General Hospital,

Southampton SO9 $4 \mathrm{XY}$

1 Barker DJP, Winter PD, Osmond C, Margetts B, Simmonds SJ. Weigh in infancy and death from ischaemic heart disease. Lancet 1989;ii:577-80.

2 Barker DJP, Bull AR, Osmond C, Simmonds SJ. Fetal and placental size and risk of hypertension in adult life. BMF 1990;301:259-62.

3 Hales CN, Barker DJP, Clark PMS, Cox LJ, Fall C, Osmond C, Winter $P D$. Fetal and infant growth and impaired glucose tolerance at age 64 . BMF 1991;303:1019-22.

4 Barker DJP, Meade TW, Fall CHD, Lee A, Osmond C, Phipps K Stirling Y. Relation of fetal and infant growth to plasma fibrinogen and factor VII concentrations in adult life. BMf 1992;304:148-52.

5 Dubos R, Savage D, Schaedler R. Biological Freudianism: lasting effects of early environmental influences. Pediatrics 1966;38:798-800.

6 Coates PM, Brown SA, Sonaware BR, Koldovsky O. Effect of early nutrition on serum cholesterol levels in adult rats challenged with a high fat diet. $\mathcal{F}$ Nutr 1983;113:1046-50.

7 Hahn P. Effect of litter size on plasma cholesterol and insulin and some liver and adipose tissue enzymes in adult rodents. $f$ Nutr 1984;114:1231.

8 Mott GE, Lewis DS, McGill HC. Programming of cholesterol metabolism by breast or formula feeding. In: The childhood environment and adulc disease. Chichester: Wiley, 1991 (Ciba Symposium 156).

9 Barker DJP, Osmond C. Infant mortality, childhood nutrition, and ischaemic heart disease in England and Wales. Lancet 1986;i:1077-81.

10 Fall CHD, Barker DJP, Osmond C, Winter PD, Clark PMS, Hales CN Relation of infant feeding to adult serum cholesterol concentration and Relation of infant feeding to adult serum cholesterol concent
death from ischaemic heart disease. $B M F 1992 ; 304: 801-5$.

11 Barker DJP, Hales CN, Fall CHD, Osmond C, Phipps K, Clark PMS Type 2 (non-insulin-dependent) diabetes mellitus, hypertension and hyperlipidaemia (syndrome $\mathrm{X}$ ): relation to reduced fetal growth Diabetologia, (in press).

12 Barker DJP, ed. Fetal and infant origins of adult disease. London: British Medical Journal, 1992.

13 Heart disease: in the beginning. Lancet 1992;339:1386-8.

14 Beischer MA, Sivasamboo R, Vohra S, Silpisorn Rosal S, Reid S Placental hypertrophy in severe pregnancy anaemia. $\mathcal{f}$ Obstet Gynaecol Br Commw 1970;77:398-409.

15 Godfrey KM, Redman CWG, Barker DJP, Osmond C. The effect of maternal anaemia and iron deficiency on the ratio of fetal weight to plamaternal anaemia and iron deficiency on the ratio of

16 McCrabb GJ, Egan AR, Hosking BJ. Maternal undernutrition during mid-pregnancy in sheep. Placental size and its relationship to calcium mid-pregnancy in sheep. Placental size and its relationship

17 Law CM, Barker DJP, Bull AR, Osmond C. Maternal and fetal influences on blood pressure. Arch Dis Child 1991;66:1291-5. 